\title{
Thiamine-Deficient Infant Formula: What Happened and What Have We Learned?
}

\author{
Raanan Shamir \\ Institute of Gastroenterology, Nutrition, and Liver Diseases, Schneider Children's Medical Center, \\ and Sackler Faculty of Medicine, Tel Aviv University, Tel Aviv, Israel
}

\section{Key Words}

B1 - Infant formula $\cdot$ Feeding $\cdot$ Regulation $\cdot$ Requirements $\cdot$ Thiamine deficiency $\cdot$ Vitamin

\begin{abstract}
Introduction: In 2003, a thiamine-deficient soy infant formula was produced in Germany and marketed exclusively in Israel. Between October and November 2003, infants with encephalopathy were admitted to several intensive care units in Israel and were later diagnosed as suffering from thiamine deficiency. The soy formula consumed by these children was found to be the cause of these admissions. Methods: A Medline search using the terms 'thiamine deficiency' and 'formula' or 'feeding' without year limit identified relevant published data on that event. Newspapers from Israel were screened from November 2003 until April 2011. Results: On November 2003, 2-6\% of infants in Israel consumed this formula. The consumption of this thiamine-deficient formula was associated with the death of 3 infants and with more than 20 infants manifesting neurologic damage. In this report, we summarize the chain of events, the neurologic outcome, and discuss the lessons needed to be learned from this sad event. Conclusions: Based on difficulties in diagnosis of subtle deficiencies, we suggest that apparent history of safe use is not a reliable source for establishing ade-
\end{abstract}

quate intake. Infant formulae can be produced or imported only under stringent criteria with the manufacturer/importer having total responsibility for the product.

Copyright $\odot 2012$ S. Karger AG, Basel

\section{Introduction}

Infant formulae are the sole source of nutrition in the first few months of life for infants who are not breast fed. In accordance with this specific nutrition scenario, the European Directive from 2006 states that the composition of infant formulae must meet all nutrition requirements of healthy infants, and this should be based on valid and accepted scientific data [1]. Furthermore, it concludes that 'given the particular nature of infant formula, additional means to those usually available to monitoring bodies should be available in order to facilitate efficient monitoring of those products'.

In 2003, a thiamine-deficient soy infant formula was produced in Germany and marketed exclusively in Israel. Between October and November 2003, infants with encephalopathy were admitted to several intensive care units in Israel and were later diagnosed as suffering from thiamine deficiency. The soy formula consumed by these children was found to be the cause of these admissions.

\section{KARGER \\ Fax +4161306 1234 \\ E-Mail karger@karger.ch}

www.karger.com
(C) 2012 S. Karger AG, Basel

0250-6807/12/0603-0185\$38.00/0

Accessible online at:

www.karger.com/anm
Raanan Shamir, MD

Institute of Gastroenterology, Nutrition, and Liver Diseases

Schneider Children's Medical Center

14 Kaplan Street, Petach-Tikva 49202 (Israel)

Tel. +972 3925 3673, E-Mail shamirraanan@gmail.com 
In this report we summarize the chain of events and the reported neurological outcome in order to delineate the steps needed to avoid future events as this one.

\section{Methods}

A Medline search using the terms 'thiamine deficiency' and 'formula' or 'feeding' without year limit identified relevant published data on that event. Newspapers from Israel were screened from November 2003 until April 2011.

\section{The 'Remedia Story'}

On November 6, 2003, a report from Schneider Children's Medical Center, affiliated with the Tel Aviv University, was issued to the Israeli Ministry of Health. On that report, it was stated that 4 infants, aged 2-10 months, with unexplained encephalopathy were admitted to the intensive care unit. Clinical signs of these infants included gastrointestinal symptoms (constipation, lack of appetite, vomiting, and later diarrhea) and neurologic symptoms, including agitation, apathy, and, later, nystagmus, convulsions, and unconsciousness [2]. All affected infants had one thing in common: all of them were fed a soy-based infant formula, distributed by Remedia under the name Remedia Super Soya 1, a formula that was manufactured specifically for Remedia by Humana Milchunion (Germany).

On November 7, 2003, the Ministry of Health issued a directive to all parents to cease use of the Remedia soybased formula and ordered that the product be removed from all points of sale and from use in medical facilities. At that time, there was no reason to suspect that the formula was thiamine deficient since the label indicated adequate amounts of the vitamin. While other cases were admitted, including a case of cardiac failure, clinical diagnosis raised suspicion of Beriberi, supported by a report from a physician who gave vitamin B1 with reversibility of most signs.

On November 9, examination of thiamine content in the three batches of Remedia soy-based infant formula revealed that thiamine could not be detected in these formulae, and on November 10, the German manufacturing company, Humana, reported that thiamine was omitted from the formula. An alert was issued to the World Health Organization, resulting in an announcement to all member states on November 21, 2003 [3].

According to Humana, an employee of the company failed to add thiamine to a new soybean product because the vitamin naturally occurs in soybeans. However, the employee did not take into account that the soy was treated with heat, resulting in a product without thiamine [4]. According to the Israeli media, the new soy product was sent for laboratory evaluation of nutrients, but the laboratory did not provide thiamine determination (although it should have done so). Humana quality control did not detect the lack of thiamine in the report, and it was shipped to Israel without the results of thiamine content. Again, according to Israeli media, a Humana employee found out that results were missing, but her superior decided that since the shipment to Israel had already occurred, there was no need for repeated testing.

In Israel, in 2003, the Ministry of Health estimated that $2-6 \%$ of the infant population, Nationwide, consumed this formula (personal communication). Not all infants were exclusively consuming the formula, and duration of feeding varied.

In a follow-up study of 20 Remedia-fed infants, after 3 years, these infants had significant lower expressive communication, auditory comprehension language subscales, Mental Developmental Index score, and reached independent walking at a later age [5]. In another study from Souraski Medical Center and Schneider Children's Medical Center, it was found that 7 infants displayed seizures upon presentation (either tonic, myoclonic, or focal), and seizure recurred in all children after a seizure-free period (either myoclonic or complex partial seizures). In 4 of the 7 children, the seizures remained uncontrolled, suggesting that severe thiamine deficiency may cause epilepsy [6]. Magnetic resonance (MR) imaging follow-up of these children revealed that thiamine deficiency was characterized by involvement of the frontal lobes and basal ganglia, in addition to the lesions in the periaqueductal region, thalami, and the mammillary bodies described in adults. Furthermore, MR spectroscopy demonstrated a characteristic lactate peak [7].

Overall, this event resulted in the death of 4 infants (3 around the acute phase and 1 after more than 6 years) with more than 20 children with severe neurologic damage. All these patients consumed the thiamine-deficient formula at the age of 2-10 months.

\section{Discussion}

Formulae are the sole source of nutrition for young infants that are not breast fed. This period is a sensitive period of rapid growth and development and, thus, deficiencies or excess of nutrients may have severe short-term 
as well as long-term consequences [8-10]. The 'Remedia story' is a sad reminder that infant formulae can be hazardous in real life, and the big question is: can it happen again?

Regardless of regulations and industry roles, stands the role of scientists to continue in the efforts to define the specific needs of infants and to ensure that recommendations consider adequate amounts in infant formulae throughout their shelve life $[8,10]$.

In addition, it seems that apparent history of safe use should cease to be a valid evidence for nutrient adequacy. Apparent history of safe use has long been used as a basis for determining minimum and maximum requirements for infant formulae, even in premature infants [11]. The fact that 3 infants had to die and more than 10 to be admitted to hospitals before a common denominator could be established calls into question the ability of apparent history of safe use as a valid tool. It is not conceivable that small differences in growth, cognitive development, and later risk of disease could be detected with this approach.

Should we inspect our formulae intensely? Currently, in the USA, manufacturers submit laboratory evaluations for each new infant formula to the Food and Drug Ad- ministration (FDA), but the agency does not retest the formulas before they go to market. The FDA, however, performs inspections of manufacturing plants yearly and collects samples for nutrient analyses [4]. Active inspection is not part of the mandate of the European Safety Agency (EFSA), and in Israel, after the thiamine-deficient formula event, all shipments have been evaluated for nutrient content, resulting in withholding shipments at airports and seaports with a considerable financial burden to the taxpayer.

It seems that the only logical solution is to leave full responsibility with the industry but be active in surveillance with occasional independent examinations.

Our conclusion is that apparent history of safe use is not a reliable source for establishing adequate intake and that infant formulae can be produced or imported only under stringent criteria with the manufacturer/importer having total responsibility for the product.

\section{Disclosure Statement}

R.S. has no conflict of interest.

\section{References}

1 Commission Directive 2006/141/EC on infant formulae and follow on formulae and amending Directive 1999/21/EC. December 22, 2006.

-2 Fattal-Valevski A, Kesler A, Sela BA, NitzanKaluski D, Rotstein M, Mesterman R, Toledano-Alhadef H, Stolovitch C, Hoffman C, Globus O: Outbreak of life-threatening thiamine deficiency in infants in Israel caused by a defective soy-based formula. Pediatrics 2005;115:233-238

3 Thiamine deficient infant formula. November 21, 2003. www.who.int/mediacentre/releases/2003/pr88/en/ (accessed April, 2011).

$\checkmark 4$ Vikhanski L: Fatal flow in baby formula sparks reform in Israeli ministry. Nat Med 2004;10:7.
5 Fattal-Valevski A, Azouri-Fattal I, Greenstein YJ, Guindy M, Blau A, Zelnik N: Delayed language development due to infantile thiamine deficiency. Dev Med Child Neurol 2009;51:629-634.

6 Fattal-Valevski A, Bloch-Mimouni A, Kivity S, Heyman E, Brezner A, Strausberg R, Inbar D, Kramer U, Goldberg-Stern H: Epilepsy in children with infantile thiamine deficiency. Neurology 2009;73:828-833.

$>7$ Kornreich L, Bron-Harlev E, Hoffmann C Schwarz M, Konen O, Schoenfeld T, Straussberg R, Nahum E, Ibrahim AK, Eshel G, Horev G: Thiamine deficiency in infants: MR findings in the brain. Am J Neuroradiol 2005;26:1668-1674.
8 Scientific Committee on Food: Report of the Scientific Committee on Food on the revision of essential requirements of infant formulae and follow-on formulae. Brussels, European Commission, 2003. SCF/CS/ NUT/IF/65 Final, 2003. http://europa.eu. int/comm/food/fs/sc/scf/out199_en.pdf (accessed March 1, 2006).

$\checkmark 9$ Koletzko B, Shamir R: Standards for infant formula milk. BMJ 2006;332:621-622.

10 Koletzko B, Baker S, Cleghorn G, Neto UF, Gopalan S, Hernell O, et al: Global standard for the composition of infant formula: recommendations of an ESPGHAN Coordinated International Expert Group. J Pediatr Gastroenterol Nutr 2005;41:584-599.

11 Klein CJ: Nutrient requirements for preterm infant formulas. J Nutr 2002;132:1395S1577 S. 